\title{
Digestion of rice straw and oil palm fronds by microflora from rumen and termite bacteria, in vitro.
}

\begin{abstract}
The digestion and Volatile Fatty Acid (VFA) production from rice straw and oil palm fronds by cellulolytic bacteria isolated from the termite Coptotermes curvignathus were investigated. The bacteria were Acinetobacter strain Raminalimon, Enterobacter aerogenes strain Razmin C, Enterobacter cloacae strain Razmin B, Bacillus cereus strain Razmin A and Chryseobacterium kwangyangense strain $\mathrm{Cb}$. Acinetobacter strain Raminalimon is an aerobic bacterium, while the other species are facultative anaerobes. There were significant differences $(p<0.05)$ among the bacteria for Dry Matter $(D M)$ lost and acetic acid production from rice straw and Acinetobacter strain Raminalimon showed the highest activity. The facultative bacteria $\mathrm{C}$. kwangyangense strain $\mathrm{Cb}$ (cfu $\mathrm{mL}(-1) 231 \times 10(-6)$, OD: 0.5), E. cloacae (cfu mL(-1) 68 x 10(-7), OD: 0.5) and E. aerogenes (cfu mL(-1) 33 x 10(-7), OD: 0.5) were used for digestion study with the rumen fluid microflora. The in vitro gas production technique was applied for the comparative study and the parameters measured were $\mathrm{pH}$, gas (volume), dry matter lost, acetic acid, propionic acid and butyric acid concentrations. $\mathrm{pH}$ was not significantly $(\mathrm{p}<0.05)$ different among the five treatments. The bacterium $\mathrm{C}$. kwangyangense strain $\mathrm{Cb}$ showed the highest activity $(\mathrm{p}<0.05)$ for DM lost, acetic acid, propionic acid and butyric acid production from rice straw when compared to the other bacterial activities. There was no significance $(\mathrm{p}<0.05)$ difference between the three bacteria for the dry matter lost of oil palm fronds but the production of Volatile Fatty Acids (VFA) was significantly $(\mathrm{p}<0.05)$ high in the treatment which was inoculated with $C$. kwangyangense strain $\mathrm{Cb}$. The Gen Bank NCBI/EMBL accession numbers for the bacterial strains are EU332791, EU305608, EU305609, EU294508 and EU169201.
\end{abstract}

Keyword: Digestibility; Rumen microflora; Cellulolytic bacteria; VFA. 